\title{
Simplified models for the interpretation of total stress measurement of embankment dams
}

\author{
Fontanella E. ${ }^{(1)}$, Pagano L..$^{(2)}$ Desideri A. ${ }^{(1)}$ \\ enzo.fontanella@uniromal.it \\ ${ }^{1}$ Department of Structural and Geotechnical Engineering, Sapienza University of Rome \\ ${ }^{2}$ Department of Civil, Architectural and Environmental Engineering, University of Naples Fed- \\ erico II
}

\begin{abstract}
The paper describes and interprets arching action problems in three zoned earth dams. The principal simplified models available for the interpretation of data records of embankment dams are used. The representativeness of vertical total stress normally monitored in earth dams is discussed. The analysis of measurements permits to investigate how a given measured quantity can be used to interpret the dam's mechanical behavior.
\end{abstract}

Keywords: Embankment dam, Monitoring data, representativeness of measurements

\section{Introduction}

The mechanical behavior and the timely identification of the phenomena that could lead dam to collapse are the main purpose of monitoring and intrepretation of measurements.

Slope instability and watertightness problems are the two categories of most feared phenomena. Their triggering can be identified by interpreting the measurements of total stress, pore pressure, seepage flows, and settlements [1], [2], [3], [4], [5],

Interpreting a measurement means defining the phenomena that conditioned its evolution and/or distribution and characterize any possible correlations with other known physical quantities.

The reference models can be derived from the knowledge of the solutions of simpler problems known in the literature with strong exemplified hypotheses, such as to ensure solutions in closed form.

Simplified models play a key role in any interpretative process. Indicate which are the most effective forms in which to organize and represent the measurements; qualitatively identify many of the factors that have affected the mechanical behavior of dam during construction and working condition; they stimulate doubts and questions about the measurements that present anomalies, suggesting when it is necessary to resort to advanced approaches; they finally guide in the selection of physical quantities that the 
advanced type model must contain in order to be able to reproduce the observed mechanical behavior.

The detailed examination of the measurements of some earth dams has allowed to check the effectiveness of the existing interpretative tools and to develop new simplified models.

The interpretative schemes that seek to establish qualitative and quantitative correlations between "cause" and "effect" magnitudes are therefore associated with representations in which both appear. For these reasons the measurements will be represented in graphs that link them to the following factors: a) load from embankment dam; b) dam geometry; c) time.

Hydraulic fracturing is a central issue in the evaluation of the safety conditions in earth dams. In general, safety against hydraulic fracturing is checked for by measuring vertical total stress, pore water pressures in the earth dam, rate of flow through the dam; water turbidity is also inspected as a warning sign for erosion phenomena [6].

The analysis of some case histories available in the literature made it possible to identify a crucial mechanism for hydraulic fracturing, namely load transfer phenomena (arching action) due to differences in stiffness between the core and the abutments.

\section{$2 \quad$ Vertical Total Stress And Arching}

In a zoned earth dam the different stiffness of materials constituting the core and abutments produces non-homogeneous distributions of vertical total stress. The load transfer leads to a reduction of stress within the dam core and an increase in the abutments.

As an example Figure 1 shows three distributions of the vertical total stress theoretically obtained along a horizontal section. The distribution obtained for homogeneous dam $\left(E_{\text {abutment }} / E_{\text {core }}=1\right)$ is very similar to the distribution of the overburden pressure. With reference to Beliche Dam geometry, even a modest increase in the stiffness of the abutment $\left(\mathrm{E}_{\text {abutment }} / \mathrm{E}_{\text {core }}=3\right)$ is able to produce a markedly discontinuous vertical total stress distribution.

A first interpretation of the vertical total stess measurements can be obtained from comparing the measurements along horizontal lines perpendicular to the longitudinal axis of the dam with the theoretical distributions of homogeneous dam or overburden pressure. 


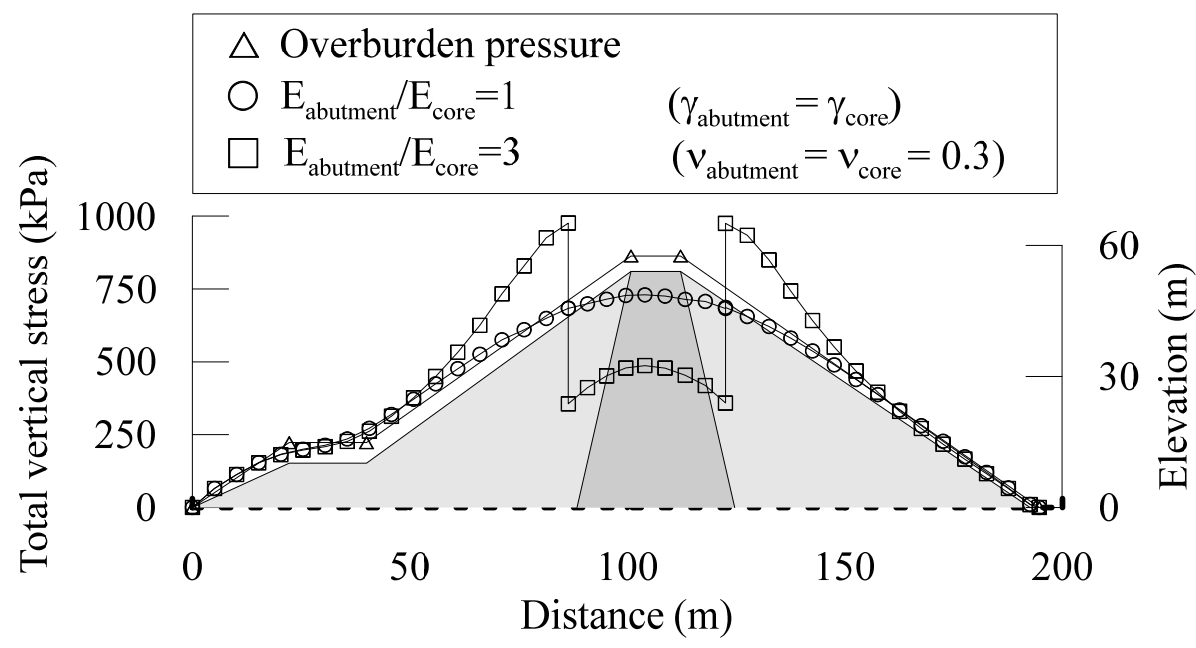

Fig. 1. - Beliche Dam: vertical total stress computed along a horizontal plane (dashed line)

Figure 2 and Figure 3 show two examples of interpretative approach above illustrated. They relate to Beliche Dam and Camastra Dam, respectively. In both cases the load transfer phenomena is highlighted with a sudden discontinuity of the values in correspondence with the core-abutment contact. For Beliche dam the comparison between measurements and computed data (model) highlights (filled circles) significant arching action. The vertical total stress measured at Camastra dam, while showing a marked arching action, are characterized by values decidedly superior to the theoretical ones. Beyond the stress concentrations produced by three-dimensional effects (not invocable in this case), the condition of vertical equilibrium in the considered section should produce distributions of vertical total stress, measured and theoretical, which subtend the same area. The marked difference between the areas subtended raise some doubts about the reliability of the measurements.

During construction of earth dam, it is possible to estimate the evolution of the arching action plotting the vertical total stress measured versus overburden pressure. In Figure 4 this plot is proposed for a point located within the core of the Kastraki Dam. The dotted line corresponds to the condition of equality between the two quantities; the greater the deviation from this condition, the greater the arching action, which leads to a load transfer towards the more rigid abutment. This type of representation is particularly effective especially in the presence of "scattered" measurement points.

In the post-construction phases vertical total stress variations can be induced by phenomena that characterize the first impounding and working condition (e.g. saturation collapse, primary consolidation, secondary compression). These are generally phenomena that induce in the generic element within the embankment deformation processes which, if contrasted by the boundary conditions, determine variations in vertical total stress. Figure 2 shows, as an example, the saturation collapse for Beliche Dam during first impounding and the change in total stress produced by the phenomenon. In the 
upstream side, subject to collapse, there is a reduction of stress, balanced, in the remaining areas of the dam, by an increase in vertical total stress.

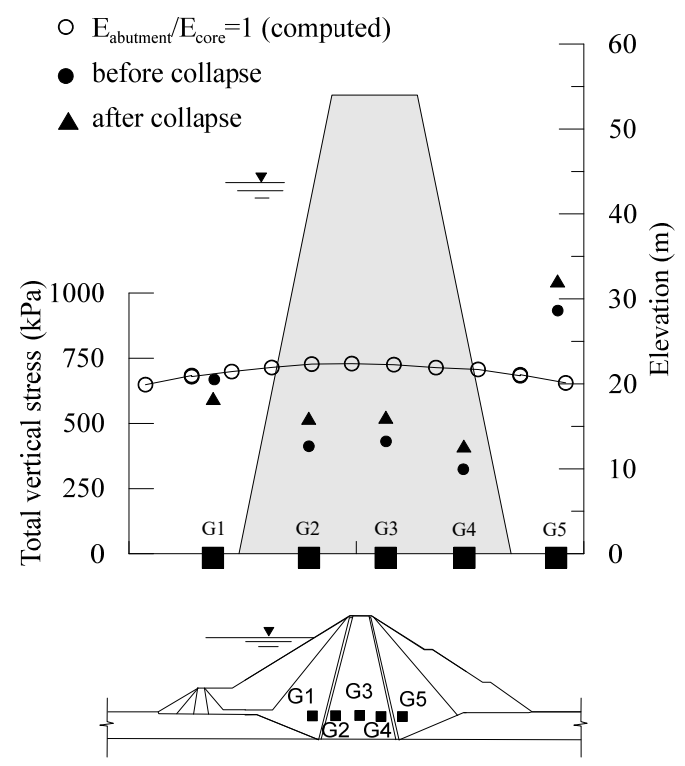

Fig. 2. - Beliche Dam: vertical total stress measured at the end of construction before anf after the temporary unexpected impounding, compared with a theoretical distribution for a homogeneous dam [Pagano, 1998, modified]

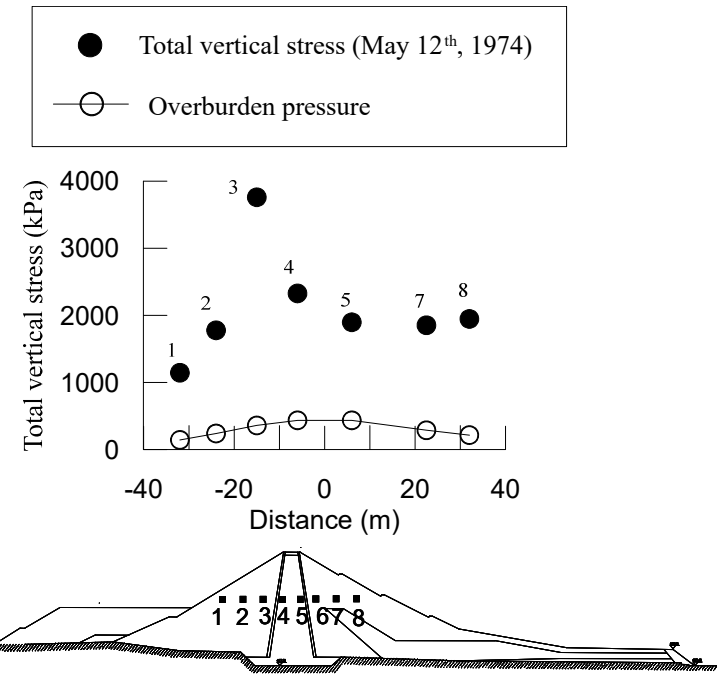

Fig. 3. - Camastra Dam: vertical total stres measured at end of construction compared with the overburden pressure 


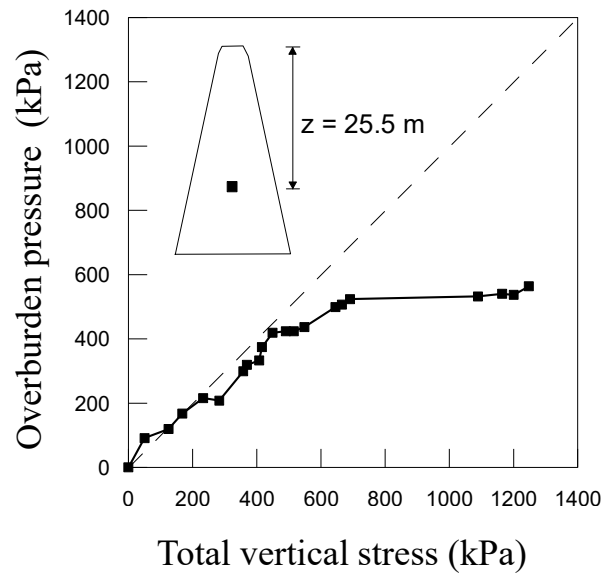

Fig. 4. - Kastraki Dam: vertical total stress measured at end of construction compared with the overburden pressure [Pagano et al., 1998]

\section{Conclusion}

In this paper the main simplified models available to understand mechanical behaviour of earth dam, were examined. The paper highlighted the main problems associated with the interpretation of the total stress measurements.

A central element of the discussion is the interpretability of measured data, linked to the concepts of reliability of measurement and representativeness of measured physical quantity.

Distribution and evolution of monitored quantities, such as total stress, aid to characterize the overall dam behaviour and detect state condition often associated to crack formation or ti diagnose hydraulic problems. When much lower than overburden pressure, vertical total stress measured in the core of a zoned earth dam indicate core arching and state conditions supposed to enhance crack formation and propagation during impounding stages.

\section{$4 \quad$ Reference}

1. Pagano, L., Desideri, A., Vinale, F.: Interpreting Settlement Profiles Of Earth Dams. Journal of Geotechnical And Geoenvironmental Engineering 124 (10), 923-932 (1998).

2. Pagano, L., Sica, S., Desideri, A.,: Representativeness of Measurements in the Interpretation of Dam Behavior. Canadian Geotechnical Journal 43(1), 87-99 (2006) 
3. Pagano, L., Fontanella, E., Sica, S., Desideri, A.: Pore water pressure measurements in the interpretation of the hydraulic behaviour of two earth dams. Soils and Foundation 50(2), 295-307 (2010).

4. Desideri, A., Fontanella, E., Pagano, L.: Pore water pressure distribution for use in stability analyses of earth dams. In: Margottini C., Canuti P., Sassa k. (eds.) Risk Assessment, Management and Mitigation 2nd World Landslide Forum, WLF 2011, vol. 6, pp. 149-153. Springer, Heidelberg (2013).

5. Fontanella, E., Pagano, L., Desideri, A.: Actual and nominal pore water pressure distribution in earth dams. Electronic Journal of Geotechnical Engineering vol.17(S), 2485-2494 (2012).

6. Penman, A.D.M.: On the embankment dam. Geotechnique 36(3), 303-348 (1986). 